\title{
The Myths Surrounding Pre-Exercise Carbohydrate Feeding
}

\author{
Asker E. Jeukendrup Sophie C. Killer \\ School of Sport and Exercise Sciences, University of Birmingham, Birmingham, UK
}

\section{Key Words}

Glucose Exercise performance $\cdot$ Timing of carbohydrate

intake Endurance

\begin{abstract}
Background/Aims: Carbohydrate ingested 30-60 min before exercise may result in hypoglycaemia during exercise, a phenomenon often called rebound or reactive hypoglycaemia. There is considerable confusion regarding pre-exercise carbohydrate feeding with advice that ranges from 'consume carbohydrate in the hour before exercise' to 'avoid carbohydrate in the $60 \mathrm{~min}$ prior to exercise'. Methods: We analysed the studies available in the literature to draw conclusions about the use of carbohydrate in the pre-exercise period. Results: Without performing a meta-analysis, it is clear that the risk of reduced performance is minimal as almost all studies point towards unaltered or even improved performance. This is despite the rather large metabolic changes that occur in response to pre-exercise carbohydrate feeding. Conclusion: It can be concluded that advice to avoid carbohydrate feeding in the hour before exercise is unfounded. Nevertheless athletes may develop symptoms sim-
\end{abstract}

ilar to those of hypoglycaemia, even though they are rarely linked to actual low glucose concentrations. An individual approach may therefore be necessary to minimize these symptoms even though they do not appear to be related to exercise performance.

Copyright $\odot 2011$ S. Karger AG, Basel

\section{Introduction}

Even textbooks can be confusing when it comes to preexercise meals. Advice ranges from 'ingest carbohydrate in the hour before' to 'avoid carbohydrate in the hour before exercise'. Early studies have outlined the metabolic effects of pre-exercise carbohydrate feeding. These include hyperinsulinaemia and hyperglycaemia before exercise followed by a rapid development of hypoglycaemia, high rates of glycogenolysis and a reduction of lipolysis and fat oxidation during exercise. Although these metabolic perturbations can in theory reduce exercise performance, the results of studies have been varied. This review will discuss the development of knowledge in this area from a historical perspective; it will discuss the evidence with regard to

\section{KARGER}

(C) 2011 S. Karger AG, Basel

Fax +41613061234

E-Mail karger@karger.ch

www.karger.com 
the metabolic effects as well as performance effects of preexercise glucose ingestion. It will also discuss the potential need for individualization and it will end with recommendations based on the currently available evidence.

\section{Historical View}

The first paper to describe the effects of pre-exercise glucose ingestion was probably a paper by Ove Boje in 1940 [1]. In this paper, it was observed that when glucose was ingested before exercise, blood glucose concentrations dropped during exercise. It was not until the 1970s that this observation was followed up. At that time the importance of muscle and liver glycogen during prolonged exercise was generally recognized. It was thought that providing additional substrate either before or during exercise should improve exercise performance. Ahlborg and Felig [2] used arteriovenous balance techniques during low-intensity exercise to study the effects of preexercise glucose feeding. Their subjects received a large amount of carbohydrate $(200 \mathrm{~g}) 50 \mathrm{~min}$ before embarking on $4 \mathrm{~h}$ of exercise at $30 \% \mathrm{VO}_{2}$ max. Several important observations were made. First, arterial glucose and insulin concentrations were high at the start of exercise. Secondly glucose uptake by the exercising legs was $40-100 \%$ greater when glucose had been ingested before exercise. Thirdly glycerol concentrations were lower suggesting a suppression of lipolysis and fat metabolism. Similar observations were made by Costill et al. [3]. They observed that ingesting glucose in the 30-45 min before exercise accelerated glycogen breakdown and induced hypoglycaemia during exercise [3].

The performance effects of pre-exercise carbohydrate feeding were first studied by Foster et al. [4]. They reported reduced endurance capacity (cycling at $80 \%$ $\mathrm{VO}_{2} \max$ to exhaustion) during the glucose trial compared with water. This paper became the basis of a recommendation that would stand for many years, namely: 'avoid carbohydrate in the hour before exercise'. A couple of years later, Koivisto et al. [5] published a paper that would become much cited. This paper reinforced the message that carbohydrate was to be avoided in the hour before exercise. In this publication, it was concluded that glucose ingested $45 \mathrm{~min}$ before exercise resulted in hyperglycaemia and hyperinsulinaemia at the onset of exercise, followed by a rapid development of hypoglycaemia during exercise. It was suggested that these effects could be prevented by using a low glycaemic index (GI) carbohydrate (fructose). In the years to follow, much at- tention was paid to this phenomenon that became known as reactive hypoglycaemia or rebound hypoglycaemia. It was generally assumed that carbohydrate ingestion prior to exercise would cause hypoglycaemia, suppress fat metabolism, accelerate glycogen breakdown and thus reduce exercise performance.

\section{Research in the Last 30 Years}

Since these early studies in the 1970s and early 1980s, large numbers of studies have investigated the effects of pre-exercise carbohydrate feeding on metabolism and performance [6-16]. Despite this wealth of information, it is not easy to draw firm conclusions about the effects on metabolism and in particular, the development of hypoglycaemia. The results of all these studies are rather mixed, most likely the results of studies using different types of carbohydrates, different modes of exercise, different intensities of exercise, different subjects (some trained, some untrained) and different timing of carbohydrate intake. Since all of these factors may affect the outcome, this makes it very difficult to compare the results and determine the exact causality of the different effects.

To clarify these results, we performed a systematic series of studies to investigate the effects of pre-exercise carbohydrate feeding $[10,12,17-19]$. All studies had a similar design and only 1 variable was changed at a time (e.g. timing of intake or type of carbohydrate). Each study had a control condition where $75 \mathrm{~g}$ of glucose was ingested $45 \mathrm{~min}$ prior to exercise. The exercise consisted of 20 min of steady-state exercise at $70 \% \mathrm{VO}_{2}$ max followed by a performance test (a time trial lasting approximately 40 min). All subjects were trained and hence representative of the main population that the advice would be aimed at. The overall conclusion of these studies was that there is no effect of pre-exercise carbohydrate feeding on performance, even though in some cases hypoglycaemia did develop. Furthermore, there was no relationship between low blood glucose concentrations and performance.

Below we will briefly discuss the metabolic events that are responsible for rebound hypoglycaemia, followed by a discussion of the effects of different amounts of carbohydrate as well as the effects of timing of intake, the type of carbohydrate and the form in which it is ingested. 


\section{Rates of Glucose Appearance versus Glucose Disappearance}

When carbohydrate is ingested, an insulin response is triggered almost instantly. It has been shown that even an artificial sweetener can result in an insulin response indicating that the carbohydrate ingested is sensed well before the arterial blood glucose concentration rises. Once the carbohydrate is absorbed, insulin is released at an increased rate from the pancreas. Interestingly, the ingested carbohydrate will blunt the hepatic glucose production [20,21]. Insulin will recruit GLUT-4 transporters to the muscle membrane and facilitate glucose uptake. Depending on the type of carbohydrate, the rate of ingestion and individual differences, plasma glucose and insulin concentrations peak 20-40 min after ingestion of a single bolus, whereas glucose uptake is increased as soon as insulin concentrations rise. When exercise is initiated in the presence of high insulin concentrations, muscle glucose uptake will be further increased through an independent calcium-dependent pool of GLUT-4 transporters [22]. The rapid decrease in blood glucose concentration seen in the first $15 \mathrm{~min}$ of exercise is the result of this rapid increase in glucose uptake that is not compensated by an increased rate of appearance of glucose. In some cases, hypoglycaemia will develop (blood glucose $<3.5 \mathrm{mmol} / \mathrm{l}$ ). However, in other cases, the glucose concentration will stay above this arbitrary threshold. The symptoms of hypoglycaemia are most likely related to a reduced delivery of glucose to the brain.

There are additional effects of carbohydrate ingestion. As more carbohydrate becomes available to the muscle, glycolysis will be stimulated [23]. This stimulation, in combination with an insulin-induced inhibition of lipolysis in both adipose tissue and muscle, results in a reduction in fat oxidation. The mechanisms of this increased carbohydrate oxidation and concomitant reduction in fat oxidation can be found in more detail in other literature $[24,25]$. Initially it was thought that the increased glycogenolysis would result in premature glycogen depletion and early onset of fatigue [3]. However, the effect is transient, approximately lasting only for the first $20 \mathrm{~min}$ of exercise. Thus, it appears that these relatively small differences in glycogen breakdown have no significant effect on exercise performance.

\section{Amount of Carbohydrate}

A study by Short et al. [26] showed that a higher insulin concentration at the start of exercise, resulting from $75 \mathrm{~g}$ carbohydrate ingestion, did not further decrease blood glucose concentrations compared with the ingestion of $22 \mathrm{~g}$ of carbohydrate. In agreement, Sherman et al. [16] did not find significantly different blood glucose responses during exercise when subjects ingested either $78 \mathrm{~g}$ or $156 \mathrm{~g}$ of a maltodextrin and glucose mixture $60 \mathrm{~min}$ before exercise. Despite higher insulin concentrations at the onset of exercise following the ingestion of $156 \mathrm{~g}$ compared with $78 \mathrm{~g}$ of carbohydrate, blood glucose concentrations in both trials decreased. Similar findings were also obtained by Jentjens et al. [11] when 25,75 or $125 \mathrm{~g}$ of carbohydrate was ingested $45 \mathrm{~min}$ prior to exercise.

Taken together, these studies suggest that the fall in blood glucose concentration during submaximal exercise (62-72\% $\left.\mathrm{VO}_{2} \mathrm{max}\right)$, following the consumption of a moderate amount of carbohydrate (75 g of carbohydrate) within the hour before exercise, cannot be prevented either by ingesting a smaller (about $22 \mathrm{~g}$ ) or a larger (more than $155 \mathrm{~g}$ ) amount of carbohydrate. Furthermore, there appear to be no performance differences when a smaller or a larger amount of carbohydrate is ingested prior to exercise.

\section{Timing of Carbohydrate Intake}

Very few studies have directly investigated the effect of timing of carbohydrate intake across a range of times in the immediate pre-exercise period. Moseley et al. [12] investigated the metabolic response to $75 \mathrm{~g}$ of glucose ingested 15, 45 or 75 min before exercise. Plasma glucose concentrations were significantly higher immediately before exercise in the $15 \mathrm{~min}$ pre-exercise feeding group compared with the $45 \mathrm{~min}$ and $75 \mathrm{~min}$ pre-exercise groups. Furthermore, insulin concentrations immediately before exercise were also significantly higher when carbohydrate was consumed 15 min before exercise compared with $45 \mathrm{~min}$ before exercise. The lowest insulin concentrations were observed when carbohydrate was ingested $75 \mathrm{~min}$ before exercise. Interestingly, differences in plasma glucose concentration disappeared within $10 \mathrm{~min}$ of exercise and no significant differences in performance were found. In addition to these findings, Pritchett et al. [27] studied the effects of a nutrient bar (20 g carbohydrate, $12 \mathrm{~g}$ protein and $4.5 \mathrm{~g}$ fat) consumed at either 15 or 60 min before exercise. Unlike Moseley et al. [12], no sig- 
nificant differences were seen in glucose concentrations between groups. It is possible that this was the result of the volume of carbohydrate consumed and its co-ingestion with other nutrients. In accordance with Moseley et al. [12], the timing of the ingestion of pre-exercise nutrition had no significant effect on exercise performance.

Although research has consistently found clear metabolic differences in response to the timing of pre-exercise carbohydrate ingestion within the hour before exercise, the performance effects have been somewhat equivocal. With the exception of 1 study [4], research has either found no performance effects [6-13] or a performance improvement [14-16]. Based on current research, it would appear that there is little evidence to suggest avoiding carbohydrate intake in the hour before exercise. Furthermore, the ingestion of carbohydrate during this period may lead to enhanced performance. Therefore, individual experimentation is required to find one's optimal preexercise nutrition routine.

To minimize the risks of hypoglycaemia, carbohydrate can be ingested just prior to exercise (in the last $5 \mathrm{~min}$ ) or during the warm-up. Brouns et al. [28] gave a carbohydrate-containing beverage (sucrose, fructose, maltodextrin, or glucose) or a placebo to subjects during a warm-up. This warm-up was followed by a short break and an exercise bout. Results showed that the warm-up and final exercise led to increased catecholamine concentrations and a blunted insulin response. Data also showed that the intake of carbohydrate-containing beverages during a warm-up followed by a small break does not lead to rebound hypoglycaemia, independent of the amount of carbohydrate ingested, but instead increases blood glucose. When carbohydrate is ingested just before exercise $(<10 \mathrm{~min})$, exercise will start before the insulin concentration has increased and therefore this timing strategy would provide the carbohydrate but minimize the risk of reactive hypoglycaemia.

\section{Glycaemic Index}

The GI is a functional tool used to categorize carbohydrates based on their blood glucose and insulin response to a known food. GI is calculated by the glucose area under the curve during approximately $2 \mathrm{~h}$ following ingestion of $50 \mathrm{~g}$ carbohydrate compared to a reference food such as glucose or white bread (GI: 100). Carbohydrates are generally categorized into either low $(<55)$, moderate $(56-70)$ or high (70-100) GI carbohydrates [29]. A low GI carbohydrate results in a slow and gradual rise in plasma glucose and insulin whereas a high GI carbohydrate results in a rapid rise in glucose and insulin concentration to peak values, before returning to baseline relatively quickly.

The GI has been widely used by exercise scientists since its introduction in $1984[30,31]$ to understand the effects of pre-exercise carbohydrate on both metabolism and exercise performance. Studies confirmed that the ingestion of high GI carbohydrates in the hour before exercise leads to elevated plasma glucose and/or insulin concentrations compared to low GI $[15,32]$ or moderate GI $[33,34]$ carbohydrates. At the onset of exercise however, these high concentrations of plasma glucose have been shown to rapidly decrease to hypoglycaemic levels $(<3.5 \mathrm{mmol} / \mathrm{l})$ within just $10-20 \mathrm{~min}$. Although it is often assumed that the reduced glycaemic response of low GI foods is due to a lower rate of appearance of glucose in the circulation, it has also been suggested that this may be due to an earlier postprandial hyperinsulinaemia and an earlier increase in the rate of disappearance of glucose, which attenuated the increase in the plasma glucose concentration [35].

Hypoglycaemia during exercise has not been observed in all individuals following the intake of high GI carbohydrates $[3,11,19,34,36]$. It is therefore thought that some individuals may be more susceptible to hypoglycaemia. It was originally proposed that insulin sensitivity may be a determinant of rebound hypoglycaemia [37]; however, Jentjens et al. [11] found no relationship between one's sensitivity to insulin and the prevalence of rebound hypoglycaemia. It is therefore still to be determined which factors contribute to an individual's susceptibility to rebound hypoglycaemia.

In addition to the more pronounced glycaemic and insulinaemic responses caused by high GI carbohydrates, there is also a trend for increased carbohydrate oxidation during exercise $[9,15,38,39]$. This occurrence is due to the increased glucose uptake and decreased plasma free fatty acids [9]. Furthermore, data have also shown that the ingestion of low GI carbohydrates 45 min before exercise increases fat oxidation during exercise compared with high GI carbohydrates [11].

Although it is clear that the GI of a carbohydrate has significant effects on metabolism when consumed before exercise, there is little evidence to suggest that there are any performance effects. Original findings by Thomas et al. [15] suggested that ingestion of low GI carbohydrates $1 \mathrm{~h}$ before exercise could increase time to exhaustion (TTE) by 20 min compared to high GI carbohydrates. Since these initial findings, a multitude of studies have taken place but few have been able to reproduce these results [11, 13, 32-34, 39, 40]. Very few studies [41] have 
shown low GI carbohydrates to improve exercise performance above high GI carbohydrates when consumed approximately $1 \mathrm{~h}$ before exercise. Studies which have used cycling time trial performance $[11,32,34,40]$ or TTE $[13$, $33,39]$ have found no significant differences in performance outcomes.

It is worth noting that when consumed $3 \mathrm{~h}$ before exercise, low GI carbohydrates do have the potential to enhance performance. Recent findings have shown significant improvements in both running TTE [42] and time trial [43] following ingestion of low GI carbohydrates compared with high GI carbohydrates consumed $3 \mathrm{~h}$ before exercise. In these studies, however, no further carbohydrate was ingested in the hour before exercise or during exercise. Most athletes will ingest additional carbohydrate approximately $1 \mathrm{~h}$ before exercise begins or may use carbohydrate during exercise and thus the practical relevance of these findings is unknown.

\section{Solid versus Liquid}

The form of carbohydrates ingested before exercise has also received attention for its potential effects on both metabolism and performance. As well as measuring exercise capacity following the consumption of liquid, semi-solid (gel) or solid forms of carbohydrate, studies have also investigated the effects of form on oxidation rates, glycogen synthesis and gastrointestinal tolerance.

The ingestion of solid food significantly slows gastric emptying, digestion and absorption rates compared with a liquid food [44]. This impacts blood glucose concentration and hence it has therefore been proposed that the intake of solid foods before exercise may be beneficial in providing a slower, more sustained release of glucose into the blood [45]. Interestingly, data from recent studies comparing ingestion of solid versus liquid carbohydrate [46] and solid versus gel carbohydrate [34] found no significant differences in blood glucose concentrations between groups. Furthermore, additional research has found no differences in either carbohydrate oxidation rates between solid versus liquid [47] or liquid versus gel [48] carbohydrate consumed during exercise. Studies that have investigated performance effects have found no significant differences following pre-exercise ingestion of solid versus liquid [49] or solid versus gel [34, 46] carbohydrates.

To summarize, there appear to be no data to suggest that one particular form of carbohydrate can enhance or reduce exercise performance over and above any other form. In addition to this, it has been shown that there is no difference in glycogen synthesis following liquid or solid carbohydrates $[50,51]$. It would therefore be advisable to ingest whichever form of carbohydrate best suits the individual athlete, based on the practical issues of consumption and cost-effectiveness of the product. It must be noted that the studies discussed above use solid foods that are high in carbohydrate and low in fat, protein and fibre. It is likely that if the macronutrient composition of the food is very different from the drink that the metabolic effects will also be different.

\section{Exercise Intensity}

Exercise intensity affects both glucose uptake by the muscle and endogenous glucose production. In order to maintain plasma glucose concentration during exercise, hepatic glucose output is elevated [20] to match the increased muscle glucose uptake [52]. During higher-intensity exercise $\left(>80 \% \mathrm{VO}_{2} \mathrm{max}\right)$, hepatic glucose output may exceed glucose uptake and elevated plasma glucose concentrations are often observed. This in turn could reduce the chances of developing hypoglycaemia. Most preexercise carbohydrate feeding studies have been performed at intensities eliciting $70 \% \mathrm{VO}_{2} \max$. While in some of these studies hypoglycaemia was reported $[5,53]$, in other studies glucose concentration did not decrease markedly $[13,38,54]$. The results of studies where subjects were asked to exercise at higher intensities $(>80 \%$ $\left.\mathrm{VO}_{2} \max \right)$ are also inconclusive. In some studies, glucose concentration did not change or increased $[49,55]$, while others have reported a decrease in glucose concentration during the first $15 \mathrm{~min}$ of exercise $[4,8,56]$. These studies that investigated the glucose response during low-intensity exercise did not describe the changes in glucose concentration during the first hours of exercise $[2,57]$. Based on these data, it seems fair to summarize that effects of exercise intensity on the development of hypoglycaemia are inconclusive. It is likely that there are large individual differences in the response to increasing exercise intensities and studies in the literature are difficult to compare because of the methodological issues mentioned above.

\section{Prevalence of Hypoglycaemia and Factors Affecting It}

From several studies it is clear that hypoglycaemia is highly individual, with some individuals very prone to development and others much more resistant. As dis- 
cussed above, factors such as the amount of carbohydrate ingested can decrease (or increase) the risk of developing hypoglycaemia. Observations from a number of studies in our lab revealed some interesting observations that have not received a lot of attention in the published literature. From these studies it appeared that some individuals are clearly more prone to develop hypoglycaemia than others. For example, in a study by Moseley et al. [12], it was observed that when carbohydrate was ingested 75 min before exercise, 5 individuals developed hypoglycaemia, when ingested 45 min before only 3 , and when ingested 15 min before only 2 (fig. 1). The 2 subjects who developed hypoglycaemia in the condition that resulted in the lowest prevalence also demonstrated hypoglycaemia in the other conditions. The subjects who developed hypoglycaemia $45 \mathrm{~min}$ before exercise also developed hypoglycaemia $75 \mathrm{~min}$ before exercise. This seems to indicate that some individuals are more prone to develop hypoglycaemia than others. As mentioned above, we also found that these individual differences could not be explained by differences in glucose tolerance as measured by an oral glucose tolerance test [11]. It is therefore still to be determined which factors contribute to an individual's susceptibility to develop hypoglycaemia.

\section{Symptoms of Hypoglycaemia Do Not Mean Hypoglycaemia}

An interesting finding of the studies in our lab was that some individuals developed symptoms of hypoglycaemia in all conditions whereas others did not develop these symptoms. Moreover, these symptoms were often reported in the absence of true hypoglycaemia. In contrast, some subjects had extremely low plasma glucose concentration but did not report any symptoms. This finding was not new. In 1979, Foster et al. [4] reported that the symptoms reported did not match the serum glucose concentrations. For example, 3 subjects reported extreme symptoms of hypoglycaemia just before stopping the ride. The blood glucose concentrations at this point were 3.7, 4.6 and $3.1 \mathrm{mmol} / \mathrm{l}$. This means that only one of these values was low enough to be classified as hypoglycaemia. On the other hand, one subject had a blood glucose value of $2.4 \mathrm{mmol} / \mathrm{l}$ at that time point but did not display any symptoms or unusual fatigue. At present, the cause of the symptoms is still unknown but it is clearly not related to a threshold blood glucose concentration. Or if it is, this threshold may be individually determined and cannot be captured by an average value of $3.5 \mathrm{mmol} / \mathrm{l}$.

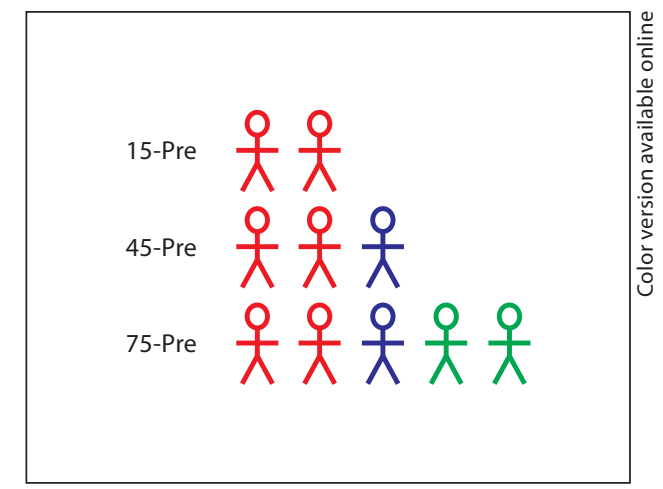

Fig. 1. Individuals who developed hypoglycaemia when carbohydrate was ingested 15, 45 or 75 min prior to exercise. Data from Moseley et al. [12].

\section{Recommendations}

Based on the currently available evidence there appears to be no reason not to consume carbohydrate before exercise as there do not seem to be any detrimental effects on performance. Individuals prone to developing reactive hypoglycaemia and/or symptoms that are often associated with it can find solutions to avoid it. These solutions could include choosing low GI carbohydrates, ingesting carbohydrate just before exercise or during a warm-up or alternatively, avoiding carbohydrate in the $90 \mathrm{~min}$ before exercise altogether.

\section{Disclosure Statement}

Asker Jeukendrup's research has been funded by the Wellcome Trust, Nestec, GSK, Cargill, GSSI, and Unilever. Sophie Killer has nothing to disclose. 


\section{References}

1 Boje O: Arbeitshypoglykämie nach Glucose Eingabe. Skand Arch Physiol 1940;83:308312.

-2 Ahlborg G, Felig P: Substrate utilization during prolonged exercise preceded by ingestion of glucose. Am J Physiol 1977;233:E188E194.

>3 Costill DL, Coyle E, Dalsky G, Evans W, Fink W, Hoopes D: Effects of elevated plasma FFA and insulin on muscle glycogen usage during exercise. J Appl Physiol 1977;43:695-699.

$\checkmark 4$ Foster C, Costill DL, Fink WJ: Effects of preexercise feedings on endurance performance. Med Sci Sports 1979;11:1-5.

5 Koivisto VA, Karonen SL, Nikkila EA: Carbohydrate ingestion before exercise: comparison of glucose, fructose, and sweet placebo. J Appl Physiol 1981;51:783-787.

6 Chryssanthopoulos C, Hennessy LC, Williams C: The influence of pre-exercise glucose ingestion on endurance running capacity. Br J Sports Med 1994;28:105-109.

7 Devlin JT, Calles-Escandon J, Horton ES: Effects of preexercise snack feeding on endurance cycle exercise. J App Physiol 1986;60: 980-985.

8 McMurray RG, Wilson JR, Kitchell BS: The effects of fructose and glucose on high intensity endurance performance. Res Q 1983;54: 156-162.

-9 Febbraio MA, Chiu A, Angus DJ, Arkinstall MJ, Hawley JA: Effects of carbohydrate ingestion before and during exercise on glucose kinetics and performance. J Appl Physiol 2000;89:2220-2226.

10 Jentjens RL, Jeukendrup AE: Effects of preexercise ingestion of trehalose, galactose and glucose on subsequent metabolism and cycling performance. Eur J Appl Physiol 2003; 88:459-465.

$\checkmark 11$ Jentjens RL, Cale C, Gutch C, Jeukendrup AE: Effects of pre-exercise ingestion of differing amounts of carbohydrate on subsequent metabolism and cycling performance. Eur J Appl Physiol 2003;88:444-452.

$\checkmark 12$ Moseley L, Lancaster GI, Jeukendrup AE: Effects of timing of pre-exercise ingestion of carbohydrate on subsequent metabolism and cycling performance. Eur J Appl Physiol 2003;88:453-458.

$\checkmark 13$ Hargreaves M, Costill DL, Fink WJ, King DS, Fielding A: Effect of pre-exercise carbohydrate feedings on endurance cycling performance. Med Sci Sports Exerc 1987;19:3336.

-14 Okano G, Takeda H, Morita I, Katoh M, Mu $\mathrm{Z}$, Miyake S: Effect of pre-exercise fructose ingestion on endurance performance in fed man. Med Sci Sports Exerc 1988;20:105-109.

15 Thomas DE, Brotherhood JR, Brand JC: Carbohydrate feeding before exercise: effect of glycemic index. Int J Sports Med 1991;12: $180-186$.
16 Sherman WM, Pedan MC, Wright DA: Carbohydrate feedings $1 \mathrm{~h}$ before exercise improve cycling performance. Am J Clin Nutr 1991;54:866-870.

17 Jentjens RLPG, Cale C, Gutch C, Jeukendrup AE: Effects of pre-exercise ingestion of differing amounts of carbohydrate on subsequent metabolism and cycling performance. Eur J Appl Physiol 2003;88:444-452.

18 Jentjens RL, Jeukendrup AE: Prevalence of hypoglycemia following pre-exercise carbohydrate ingestion is not accompanied by higher insulin sensitivity. Int J Sport Nutr Exerc Metab 2002;12:398-413.

19 Achten J, Jeukendrup AE: Effects of pre-exercise ingestion of carbohydrate on glycaemic and insulinaemic responses during subsequent exercise at differing intensities. Eur J Appl Physiol 2003;88:466-471.

20 Marmy-Conus N, Fabris S, Proietto J, Hargreaves $M$ : Preexercise glucose ingestion and glucose kinetics during exercise. J Appl Physiol 1996;81:853-857.

21 Jeukendrup AE, Raben A, Gijsen A, Stegen JH, Brouns F, Saris WH, Wagenmakers AJ: Glucose kinetics during prolonged exercise in highly trained human subjects: effect of glucose ingestion. J Physiol (Lond) 1999;515: 579-589.

-22 Douen A, Ramlal T, Rastogi S, Bilan P, Cartee G, Vranic M, Holloszy J, Klip A: Exercise induces recruitment of the 'insulin-responsive glucose transporter'. Evidence for distinct intracellular insulin- and exercise-recruitable transporter pools in skeletal muscle. J Biol Chem 1990;265:13427-13430.

23 Coyle EF, Jeukendrup AE, Wagenmakers AJM, Saris WHM: Fatty acid oxidation is directly regulated by carbohydrate metabolism during exercise. Am J Physiol 1997;273:E268E275.

24 Jeukendrup AE: Regulation of fat metabolism in skeletal muscle. Ann NY Acad Sci 2002;967:217-235.

25 Jeukendrup AE: Modulation of carbohydrate and fat utilization by diet, exercise and environment. Biochem Soc Trans 2003;31: 1270-1273.

26 Short KR, Sheffield-Moore M, Costill DL: Glycemic and insulinemic responses to multiple preexercise carbohydrate feedings. Int J Sport Nutr 1997;7:128-137.

27 Pritchett K, Bishop P, Pritchett R, Kovacs M, Davis J, Casaru C, Green M: Effects of timing of pre-exercise nutrient intake on glucose responses and intermittent cycling performance. S Afr J Sports Med 2008;3:86-90.

28 Brouns F, Rehrer NJ, Saris WHM, Beckers E, Menheere P, ten Hoor F: Effect of carbohydrate intake during warming up on the regulation of blood glucose during exercise. Int J Sports Med 1989;10:S568-S575.
29 Foster-Powell K, Holt SH, Brand-Miller JC: International table of glycemic index and glycemic load values: 2002. Am J Clin Nutr 2002;76:5-56.

30 Jenkins DJ, Wolever TM, Taylor RH, Barker $\mathrm{H}$, Fielden $\mathrm{H}$, Baldwin JM, Bowling AC, Newman HC, Jenkins AL, Goff DV: Glycemic index of foods: a physiological basis for carbohydrate exchange. Am J Clin Nutr 1981;34:362-366.

-31 Jenkins DJA, Wolever TMS, Jenkins AL, Josse RG, Wong GS: The glycaemic response to carbohydrate foods. Lancet 1984;ii:388391.

32 Febbraio MA, Keenan J, Angus DJ, Campbell SE, Garnham AP: Preexercise carbohydrate ingestion, glucose kinetics, and muscle glycogen use: effect of the glycemic index. J Appl Physiol 2000;89:1845-1851.

33 Kirwan JP, Cyr-Campbell D, Campbell WW, Scheiber J, Evans WJ: Effects of moderate and high glycemic index meals on metabolism and exercise performance. Metabolism 2001;50:849-855.

$>34$ Kern M, Heslin CJ, Rezende RS: Metabolic and performance effects of raisins versus sports gel as pre-exercise feedings in cyclists. J Strength Cond Res 2007;21:1204-1207.

35 Schenk S, Davidson CJ, Zderic TW, Byerley LO, Coyle EF: Different glycemic indexes of breakfast cereals are not due to glucose entry into blood but to glucose removal by tissue. Am J Clin Nutr 2003;78:742-748.

36 Hargreaves M, Costill DL, Katz A, Fink WJ: Effect of fructose ingestion on muscle glycogen usage during exercise. Med Sci Sports Exerc 1985; 17:360-363.

37 Kuipers H, Fransen EJ, Keizer HA: Pre-exercise ingestion of carbohydrate and transient hypoglycemia during exercise. Int J Sports Med 1999;20:227-231.

38 Sparks MJ, Selig SS, Febbraio MA: Pre-exercise carbohydrate ingestion: effect of the glycemic index on endurance exercise performance. Med Sci Sports Exerc 1998;30:844849.

39 Stannard SR, Constantini NW, Miller JC: The effect of glycemic index on plasma glucose and lactate levels during incremental exercise. Int J Sport Nutr Exerc Metab 2000; 10:51-61.

40 Horowitz JF, Coyle EF: Metabolic effects to pre-exercise meals containing various carbohydrates and fats. Med Sci Sports Exerc 1992;24:S724.

41 Moore LJ, Midgley AW, Thurlow S, Thomas G, Mc Naughton LR: Effect of the glycaemic index of a pre-exercise meal on metabolism and cycling time trial performance. J Sci Med Sport 2010;13:182-188.

42 Wu CL, Williams C: A low glycemic index meal before exercise improves endurance running capacity in men. Int J Sport Nutr Exerc Metab 2006;16:510-527. 
43 Wong S, Siu PM, Lok A, Chen YJ, Morris J, Lam CW: Effect of the glycemic index of preexercise carbohydrate meals on running performance. Eur J Sport Sci 2008;8:23-33.

44 Schoenfeld J, Evans D, Goebell H, Wingate $\mathrm{D}$ : The ingestion of solid food significantly slows gastric emptying, digestion and absorption rates compared with a liquid food. Digestion 1997;58:402-406.

-45 Coleman E: Update on carbohydrates: solid versus liquid. Int J Sports Nutr 1994;4:80-88.

-46 Campbell C, Prince D, Braun M, Applegate E, Casazza GA: Carbohydrate-supplement form and exercise performance. Int J Sport Nutr Exerc Metab 2008;18:179-190.

47 Pfeiffer B, Stellingwerff T, Zaltas E, Jeukendrup AE: Oxidation of solid versus liquid carbohydrate sources during exercise Med Sci Sports Exerc 2010;42:2030-2037.
48 Pfeiffer B, Stellingwerff T, Zaltas E, Jeukendrup AE: Carbohydrate oxidation from a semi-solid carbohydrate gel compared to a drink during exercise. Med Sci Sports Exerc, in press.

49 Neufer PD, Costill DL, Flynn MG, Kirwan JP, Mitchell JB, Houmard J: Improvements in exercise performance: effects of carbohydrate feedings and diet. J Appl Physiol 1987; 62:983-988.

50 Burke LM, Kiens B, Ivy JL: Carbohydrates and fat for training and recovery. J Sports Sci 2004;22:15-30.

51 Jentjens R, Jeukendrup A: Determinants of post-exercise glycogen synthesis during short-term recovery. Sports Med 2003;33: 117-144.

52 Wahren J, Felig P, Ahlborg G, Jorfeldt L: Glucose metabolism during leg exercise in man. J Clin Invest 1971;50:2715-2725.

-53 Coyle EF, Coggan AR, Hemmert MK, Lowe RC, Walters TJ: Substrate usage during prolonged exercise following a preexercise meal. J Appl Physiol 1985;59:429-433.
54 Costill DL, Coyle E, Dalsky G, Evans W, Fink W, Hoopers D: Effects of elevated plasma FFA and insulin on muscle glycogen usage during exercise. J App Physiol 1977;43:695699.

55 Bonen A, Malcolm SA, Kilgour RD, MacIntyre KP, Belcastro AN: Glucose ingestion before and during intense exercise. J Appl Physiol 1981;50:766-771.

56 Bonen A, Belcastro AN, MacIntyre K, Gardner J: Hormonal responses during intense exercise preceded by glucose ingestion. Can J Appl Sport Sci 1980;5:85-90.

57 Greenhaff PL, Gleeson M, Maughan RJ: The effects of dietary manipulation on blood acid-base status and the performance of high intensity exercise. Eur J Appl Physiol Occup Physiol 1987;56:331-337. 